\title{
A layer-averaged relative humidity profile retrieval for microwave observations: design and results for the Megha-Tropiques payload
}

\author{
R. G. Sivira ${ }^{1, *}$, H. Brogniez ${ }^{1}$, C. Mallet ${ }^{1}$, and Y. Oussar ${ }^{2}$ \\ ${ }^{1}$ Université Versailles St-Quentin; Sorbonne Universités, UPMC Univ. Paris 06; CNRS/INSU, \\ LATMOS-IPSL, Guyancourt, France \\ ${ }^{2}$ Laboratoire de Physique et d'Etudes des Matériaux (LPEM), UMR8213, ESPCI-ParisTech, Paris, France \\ *now at: Meteo Protect SAS, Paris, France
}

Correspondence to: H. Brogniez (helene.brogniez@latmos.ipsl.fr)

Received: 1 August 2014 - Published in Atmos. Meas. Tech. Discuss.: 3 September 2014

Revised: 21 January 2015 - Accepted: 6 February 2015 - Published: 4 March 2015

\begin{abstract}
A statistical method trained and optimized to retrieve seven-layer relative humidity $(\mathrm{RH})$ profiles is presented and evaluated with measurements from radiosondes. The method makes use of the microwave payload of the Megha-Tropiques platform, namely the SAPHIR sounder and the MADRAS imager. The approach, based on a generalized additive model (GAM), embeds both the physical and statistical characteristics of the inverse problem in the training phase, and no explicit thermodynamical constraint - such as a temperature profile or an integrated water vapor content - is provided to the model at the stage of retrieval. The model is built for cloud-free conditions in order to avoid the cases of scattering of the microwave radiation in the 18.7-183.31 GHz range covered by the payload. Two instrumental configurations are tested: a SAPHIR-MADRAS scheme and a SAPHIR-only scheme to deal with the stop of data acquisition of MADRAS in January 2013 for technical reasons. A comparison to learning machine algorithms (artificial neural network and support-vector machine) shows equivalent performance over a large realistic set, promising low errors (biases $<2.2 \% \mathrm{RH}$ ) and scatters (correlations $>0.8)$ throughout the troposphere (150-900 hPa). A comparison to radiosonde measurements performed during the international field experiment CINDY/DYNAMO/AMIE (winter 2011-2012) confirms these results for the mid-tropospheric layers (correlations between 0.6 and 0.92), with an expected degradation of the quality of the estimates at the surface and top layers. Finally a rapid insight of the estimated large-scale RH field from Megha-Tropiques is presented and compared to ERA-Interim.
\end{abstract}

\section{Introduction}

The atmospheric water vapor is a key parameter of the climate system and the understanding of its variation under a climate evolution relies on a thorough documentation of its horizontal and vertical distributions (Held and Soden, 2000; Roca et al., 2010; Sherwood et al., 2010). It is a major greenhouse gas, part of a strong positive feedback that amplifies the warming caused by increases of greenhouse gases in the atmosphere (Spencer and Braswell, 1997; Hall and Manabe, 2000; Held and Soden, 2006), and, because of its short life cycle compared to other species, its distribution is mainly influenced by natural processes that occur at all scales, from the large scale cells of the atmospheric circulation to the scale of the hydrometeor (e.g., Houze and Betts, 1981; Pierrehumbert and Roca, 1998; Pierrehumbert et al., 2007).

While direct measurements by radiosondes are the most simple ways to look at the vertical structure of the relative humidity $(\mathrm{RH})$ field, the network of stations (permanent or not) is unequally distributed between the two hemispheres and there is a clear gap of data over the oceans (Durre et al., 2006). The climate record built by aggregating the observations from the various operational sensors used worldwide (e.g., Vaïsala, MEISEI, IM-MK3, MODEM) requires regular intercomparison campaigns, such as those organized by the World Meteorological Organization (Nash et al., 2005), and the development of dedicated correction schemes in order to correct most of the observational errors (such as the drying effect of the radiative heating on the Vaiisala sensor or the insensitivity of the MEISEI system un- 
der dry conditions). Quite recently Wang and Zhang (2008) have summarized the systematic instrumental biases between several versions of the Vaiisala system that, if uncorrected, would affect analyses of the global moisture field. An alternative is the fleet of space-borne radiometers with channels located in spectral bands sensitive to the absorption by water vapor. Such instruments provide a more global sight of the distribution of the water vapor field since the late $1970 \mathrm{~s}$, in the thermal infrared (IR) (in the $6.3 \mu \mathrm{m}$ band) and in the microwave (MW) domain (in the $183.31 \mathrm{GHz}$ absorption line). One can mention, among others, the successive imagers of METEOSAT (Meteorological satellite, EUMETSAT) and of GOES (Geostationary Operational Environmental Satellite, NOAA); the sounders HIRS (High resolution Infrared Radiation Sounder, NOAA), AIRS (Atmospheric Infrared Sounder, NASA), IASI (Infrared Atmospheric Sounding Interferometer, EUMETSAT and CNES) and CrIS (Crosstrack Infrared Sounder, NASA); and the microwave sounders AMSU-B (Advanced Microwave Sounding Unit-B, NOAA), MHS (Microwave Sounding Unit, EUMETSAT), MWHS (Microwave Humidity Sounder, CMA) and ATMS (Advanced Technology Microwave Sounder, NASA). One can browse the OSCAR web page (Observing Systems Capability Analysis and Review tool) of the WMO (World Meteorological Organization) for an exhaustive list of the past, current and planned missions (http://www.wmo-sat.info/oscar/). However, these so-called "water vapor" channels provide indirect estimations of the RH since they measure the upwelling radiation. Estimation of the RH from these measurements are thus strongly linked to the constraints of the underlying inverse problem $(\mathrm{RH}=f$ (radiation) $)$.

Upper tropospheric humidity (UTH) can be one way to interpret these "water vapor" measurements. The retrieval of UTH was initiated by Schmetz and Turpeinen (1988) and Soden and Bretherton (1993) for observations in the $6.3 \mu \mathrm{m}$ band and successfully applied to $183.31 \mathrm{GHz}$ measurements by Spencer and Braswell (1997), Buehler et al. (2005) or Brogniez and Pierrehumbert (2006). The logarithmic transformation of the BT into UTH is quite simple and elegant. It relies on a large training data set that provides the parameters of the transformation and on a precise definition of UTH: a mean RH value vertically weighted by a dedicated function (a so-called sensitivity function) that is related to the transmission of the atmosphere in the spectral domain. The wellknown drawback of this method is that the weighting operator used to define the UTH has a width and altitude of peak that depend on both the absorber amount and on the temperature profile: the drier the atmosphere (i.e., higher BTs), the thicker the layer, and the peak of maximum of sensitivity shifts downwards. Therefore, there is no pressure attribution of the area of the troposphere under consideration.

The first aim of this study is to perform an analysis of the contribution of the two microwave instruments of the Megha-Tropiques mission, operating since October 2011, for the retrieval of layer-averaged RH profiles. The SAPHIR sounder and the MADRAS imager are both dedicated to improving the documentation of the atmospheric water cycle. In a previous paper, Brogniez et al. (2013) showed the expected improvements for the estimation of the RH profiles thanks to the combination of those two instruments, highlighting the gain of information for both ends of the troposphere when only a subset of the channels of MADRAS are combined to SAPHIR measurements. Despite the short lifetime of MADRAS, the availability of a few months of measurements constitutes a test bed for future missions, such as the Second Generation of the Meteorological Operational satellite program (MetOp-SG, EUMETSAT Polar Satellite) planned for launch in 2020. Indeed, the Microwave Sounder (MWS) and the Microwave Imager (MWI) of MetOp-SG have channels very close to those of SAPHIR and MADRAS.

The second objective is to demonstrate the potential of purely statistical methods in the following problem: given a set of brightness temperatures (BTs) provided by a spaceborne radiometer, what is the vertical distribution of $\mathrm{RH}$ and what are the expected limits of such an approach? Many retrieval approaches exist; however, to our knowledge, a few of them estimate the RH profile from a simple input data set restricted to the BTs. Indeed, most of the approaches are physically based iterative techniques such as a $n$-dimensional variational algorithm that converges to the least biased profile using other inputs as prior knowledge of the system under study (such as surface emissivity, temperature profile and sometimes a prior water vapor profile for BT simulations). These variational techniques are well established (Kuo et al., 1994; Cabrera-Mercadier and Staelin, 1995; Rieder and Kirchengast, 1999; Blankenship et al., 2000; Liu and Weng, 2005) and it would be unnecessary to reinvent a similar algorithm. Here, the selected approach is to learn the relationship between the inputs (i.e., the BTs) and the output (i.e., the averaged RH in a specific atmospheric layer) directly from a training set that implicitly contains all the relevant information such as the statistical distribution of the atmospheric $\mathrm{RH}$ or the radiative transfer equation from the set of BTs. We chose not to discuss the relevant a priori constraints that could improve the retrieval or on the choice of a relaxation scheme.

The current operational retrieval (version 6, released in 2013) of water vapor profiles (layer and level products) from the instruments of the Aqua mission (namely AIRS, AMSU and HSB (Humidity Sounder for Brazil, INPE), see Aumann et al., 2003) differs from these approaches (Fetzer et al., 2013): a stochastic approach combined with a neuralnetwork defines the first guesses of clear-air temperature and humidity profiles following Blackwell (2005) instead of a climatology in the previous version. Above $118 \mathrm{hPa}$, the water vapor profiles are filled with a climatology from the ECMWF IFS model (European Center for Medium-Range Weather Forecasts/Integrated Forecasting System). The final profiles are obtained from a physically based iterative procedure that adjusts the transmittance of the radiative transfer model. This 
algorithm requires either both IR and MW measurements (AIRS + AMSU) or IR-only measurements (AIRS) and forecast surface pressures, which are taken from the ECMWF forecasts. This last version is currently under evaluation, but first performance analyses using radiosondes measurements as a reference show an improvement of the estimation of water vapor in the mid and lower troposphere that is related to the new definition of the first guesses and to the cloudclearing methodology (Van Dang et al., 2012).

As in Brogniez et al. (2013), the retrieval technique is based on the Generalized Additive Model (hereafter GAM, Hastie and Tibshirani, 1990) and its ability to model multivariate and non-linear relationships. The choice of GAM over other retrieval techniques is relatively subjective. So to ensure that the main patterns are independent from the choice of the statistical model, a comparison against two other models is done. We consider two other machine learning regression methods based on different design algorithms and different learning techniques. A multi-layer perceptron (MLP), which is a neural-network, and a least squares support vector machine (LS-SVM), which is a kernel method. The MLP, as defined by Rumelhart et al. (1986), is generally considered as reference because it is the most common approach to develop non-parametric and non-linear regression in various application domains. MLPs have been successfully applied in remote sensing application, with or without prior information (e.g., Mallet et al., 1993; Cabrera-Mercadier and Staelin, 1995; Aires and Prigent, 2001; Franquet, 2003; Karbou et al., 2005; Aires et al., 2010). The second one is the least squares support vector machines (LS-SVMs) (Suykens et al., 2002), which belongs to the family of kernel methods. LS-SVMs are models with high generalization capabilities and numerous analysis involving real data in other areas (Balabin and Lomakina, 2011; Wun-Hua et al., 2006) have shown that SVMbased techniques are comparable in efficiency to MLPs.

The description of the data at hand and of the context of the work is made in Sect. 2. The three non-linear models, GAM, MLP and LS-SVM and their design for the study are detailed in Sect. 3. Section 4 is dedicated to the evaluation of the estimations over a realistic data set in order to have a large sample of evaluation. The application to Megha-Tropiques measurements is discussed in Sect. 5 with a comparison to radiosonde measurements. Section 6 finally draws a conclusion on the study and discuss the ongoing work.

\section{Data and context}

\subsection{Overview of the Megha-Tropiques mission}

Megha-Tropiques is an Indo-French satellite that is dedicated to the observation of the energy budget and of the water cycle within the tropical belt $\left( \pm 30^{\circ}\right.$ in latitude). The platform carries four instruments: MADRAS, a microwave imager for the observation of rain and clouds (Microwave
Analysis and Detection of Rain and Atmospheric Structures), SAPHIR, a microwave sounder of tropospheric RH (Sondeur Atmosphérique du Profil d'Humidité Intertropicale par Radiométrie), ScaRaB, a wide band instrument for the measurement of radiative fluxes at the top of the atmosphere (Scanner for Radiation Budget), and ROSA, a GPS receiver (Radio Occultation Sounder for the Atmosphere). In this study, we focus on the combined use of SAPHIR and MADRAS observations, whose characteristics are listed in Table 1 together with their in-flight radiometric sensitivities as estimated by the CNES space agency (Karouche et al., 2012). SAPHIR is the main instrument for $\mathrm{RH}$ profiling with six channels in the 183.31 GHz strong absorption line of water vapor. The first channel is close to the center of the line and is aimed at reaching the upper levels of the troposphere while the sixth channel is located on the wings of the absorption line and provides a deeper sounding of the atmosphere. In the context of the RH estimations, the measurements provided by MADRAS (dedicated to rainfall estimation) will obviously better constrain the problem since $23.8 \mathrm{GHz}$ measurements are generally used for the determination of the total water vapor content (Schaerer and Wilheit, 1979) and the two $157 \mathrm{GHz}$ channels can help removing the contribution of the surface to the upwelling radiation (English et al., 1994). However, due to a mechanical anomaly affecting the rotating mechanism of MADRAS, its measurements are considered invalid since 26 January 2013 and only SAPHIR observations are available to the scientific community after this date (joint CNES and ISRO communication done on 24 September 2013).

\subsection{Data description}

High quality RH soundings sampling the tropical troposphere, reasonably collocated in space and time with MeghaTropiques observations are quite scarce, yielding to use a synthetic training set to overcome the problem. This set is made of thermodynamical profiles representative of the $30^{\circ} \mathrm{N}-30^{\circ} \mathrm{S}$ atmosphere and of the associated BTs simulated using a radiative transfer model. This method embeds both the physical and statistical characteristics of the inverse problem in the training phase.

\subsubsection{The radiosonde profiles}

The RH profiles come from the Analyzed RadioSoundings Archive (ARSA, http://ara.abct.lmd.polytechnique.fr/ index.php?page $=$ arsa) that is a reprocess of the operational radiosoundings used in the ECMWF assimilation model, performed by the Laboratoire de Métérologie Dynamique (N. Scott, LMD, personal communication, 2015). The main aspects of the reprocess are (i) the discarding of incomplete profiles both in temperature (threshold of $30 \mathrm{hPa}$ ) and humidity (threshold of $350 \mathrm{hPa}$ ), (ii) a vertical extrapolation of the remaining profiles up to $2 \times 10^{-3} \mathrm{hPa}$, considered to be the top of the atmosphere, using space-time collocated profiles 
Table 1. Observational characteristics of SAPHIR and MADRAS. $\theta_{\text {zen }}$ is the viewing zenith angle. "H" and "V" correspond respectively to the horizontal and vertical polarizations of the observed electromagnetic field. $f_{0}$ corresponds to SAPHIR central frequency at $183.31 \mathrm{GHz}$. The instrumental noises obtained from in-orbit performance are also indicated (from Karouche et al., 2012).

\begin{tabular}{c|cc|c|c|c}
\hline Instrument & \multicolumn{2}{|c|}{$\begin{array}{c}\text { Central frequency } \\
(\text { name })\end{array}$} & $\begin{array}{c}\text { Bandwidth } \\
(\mathrm{GHz})\end{array}$ & $\begin{array}{c}\text { Resolution }(\mathrm{km}) \\
(\mathrm{MHz})\end{array}$ & $\begin{array}{c}\text { In-orbit instrumental } \\
\text { Noise }(\mathrm{NE} \Delta T(\mathrm{~K}))\end{array}$ \\
\hline & $\mathrm{S} 1$ & $f_{0} \pm 0.2$ & \pm 200 & & 1.44 \\
SAPHIR & $\mathrm{S} 2$ & $f_{0} \pm 1.1$ & \pm 350 & from $(10 \times 10) \mathrm{km}^{2}$ at nadir & 1.05 \\
cross-track & $\mathrm{S} 3$ & $f_{0} \pm 2.8$ & \pm 500 & to $(14.5 \times 22.7) \mathrm{km}^{2}$ & 0.91 \\
$\left(\theta_{\text {zen }}= \pm 50.7^{\circ}\right)$ & $\mathrm{S} 4$ & $f_{0} \pm 4.2$ & \pm 700 & on the edge of the swath & 0.77 \\
& $\mathrm{~S} 5$ & $f_{0} \pm 6.6$ & \pm 1200 & & 0.63 \\
& $\mathrm{~S} 6$ & $f_{0} \pm 11.0$ & \pm 2000 & & 0.54 \\
\hline & M1 \& M2 & $18.7(\mathrm{H} \& \mathrm{~V})$ & \pm 100 & & $0.48 \& 0.56$ \\
MADRAS & M3 & $23.8(\mathrm{~V})$ & \pm 200 & $(67.25 \times 40) \mathrm{km}^{2}$ & 0.49 \\
$\left(\theta_{\text {zen }}=53.5^{\circ}\right)$ & M4 \& M5 & $36.5(\mathrm{H} \& \mathrm{~V})$ & \pm 500 & & $0.40 \& 0.40$ \\
& M8 \& M9 & $89.0(\mathrm{H} \mathrm{\&} \mathrm{V)}$ & \pm 1350 & $(16.81 \times 10) \mathrm{km}^{2}$ & $0.55 \& 0.53$ \\
\hline
\end{tabular}

from ECMWF Reanalysis (ERA) Interim outputs and (iii) a projection on a 43-level fixed pressure grid with a surface level extracted from surface reanalyses files of ECMWF. An evaluation of the resulting profiles against IASI, MHS or HIRS/4, using a radiative transfer model has led to empirically correct the ERA-Interim profiles around $300 \mathrm{hPa}$, which can be explained by the lack of observational constraints (in situ or space-borne) in the model.

In the current study, the profiles are vertically restricted to the troposphere (from the surface up to $85 \mathrm{hPa}$ ) simply because of the characteristics of the weighting functions of SAPHIR. Figure 1a shows the profiles sampled from ARSA (mean and standard deviation) together with the six tropically averaged weighting functions of SAPHIR that do not go beyond (on average) the tropopause. We also applied a physical constraint on the RH in order to remove the extremely dry profiles $(\mathrm{RH}<2 \%)$ and the super-saturated layers encountered in the upper troposphere (RH $>150 \%$, e.g., Gierens et al. (1999), Read et al. (2007), Read et al. (2001), the RH being defined with respect to ice or liquid water depending on pressure and temperature). In the following the term RH will refer to the relative humidity computed with respect to the liquid phase of water only.

Only clear-sky conditions are considered. Indeed, as underlined by Brogniez et al. (2013), the representation of the cloudy conditions in a training database still presents a limit because reference profiles of cloudy situations with known uncertainties are difficult to gather, which could introduce unwanted additional errors in the methodology. Moreover, we chose to restrict the main part of the current work to a full description of the retrieval models dedicated to oceanic situations. The retrieval models for land surfaces have a similar design and we will mainly discuss the approach followed to consider the extremely variable continental emissivity (Karbou et al., 2005).
The base is finally made of 1631 thermodynamic 22-level profiles that cover the tropical oceans $\left(30^{\circ} \mathrm{S}-30^{\circ} \mathrm{N}\right)$ over the 1990-2007 period. Figure 1b shows the evolution of the total column water vapor (TCWV) with the surface temperature within the base. The increase of TCWV as the surface temperature increases is a well-known and strong characteristic of the tropical oceanic atmosphere, which is largely (but not entirely) explained by the Clausius-Clapeyron law (Stephens, 1990). A few profiles sample conditions associated to extremely dry (TCWV $<20 \mathrm{~mm}$ ) and very moist (TCWV > $80 \mathrm{~mm}$ ) columns.

\subsubsection{Definition of the considered atmospheric layers}

Given a set of BTs, the expected accuracy in the estimated RH will obviously highly depend on the atmospheric area under consideration. Therefore for a specific atmospheric layer, the relevant inputs will not be necessarily the same as for the layer above. One can indeed expect that the estimation of RH in the mid-troposphere will not significantly benefit from MADRAS measurements, while these should be an asset for a surface layer. This is why layer-dependent models are considered here. The RH profiles were analyzed to group the 22 original levels in relatively homogeneous layers. First, the analysis of the variance-covariance matrix determined groups of correlated successive levels. Then, self-organized maps (SOM also named Kohonen maps) (Kohonen, 1982, 2001) made of $10 \times 10$ elements (artificial neurons) are used to visualize the 22-D original profiles as $222-\mathrm{D}$ images (not shown). Here, each neurons represent a cluster of RH profiles close to one another in terms of Euclidian distance. This visual analysis allows to group the original levels with similar patterns taking into account linear and nonlinear relationships. This visualization is also used to analyze the patterns of the errors of estimation. The analysis of these SOM yields to combine the original pressure levels with a semi-empirical 

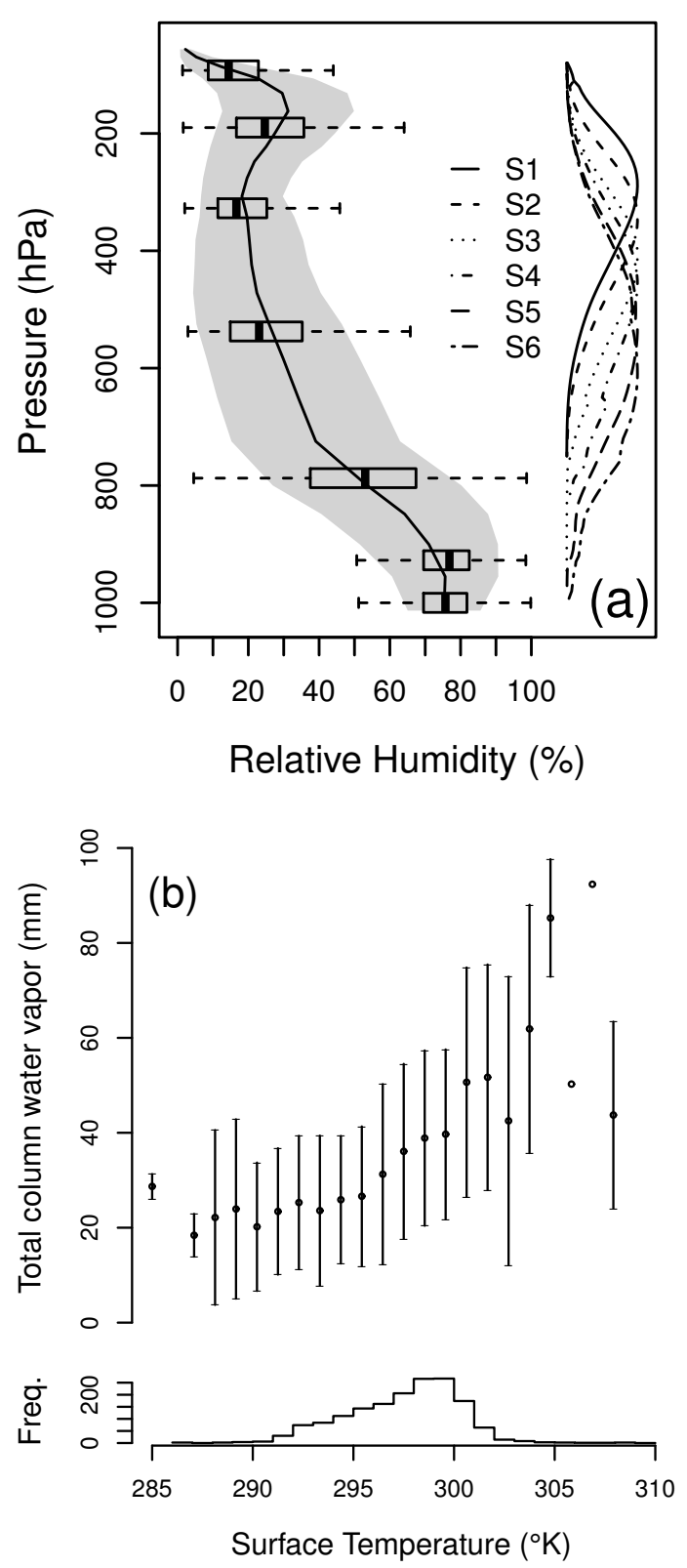

Figure 1. Characteristics of the database. (a) Distribution of total column water vapor $(\mathrm{mm})$ according to the surface temperature $(\mathrm{K})$. The top panel represents the average plus or minus 1 standard deviation. The number of observations is represented in the bottom panel. (b) The initial 22-level RH profiles are summarized by their mean (black line) and their standard deviation (grey envelope) and the reduced seven-layer clustering using box-and-whiskers diagram. For each layer, the box-and-whiskers diagram indicates the median (the central vertical line), and the lower and upper quartiles (left and right edges of the box). The whiskers indicate the lower and upper limits of the distribution within 1.5 times the interquartile range from the lower and upper quartiles, respectively. The tropical mean normalized weighting functions of SAPHIR are also represented on the side (no scale). S1...S6 refers to SAPHIR channels (see Table 1). iterative method in order to have layers with minimal variance of RH and minimal mean-median distance. From this reduction, the training RH data set is composed of sevenlayer profiles (grossly: 85-100, 130-250, 275-380, 425-650, 725-850, 900-955 and $1013 \mathrm{hPa}$ ).

Figure 1a shows the result of this vertical reduction using box-and-whiskers diagrams in order to present the main characteristics of the atmospheric layers (median, first and third quartiles, upper and lower limits of the distribution). The weighting functions of SAPHIR recall that this radiometer is designed to focus on the free troposphere (layers 3 to 6 ), with very little information near the tropopause and in the boundary layer.

\subsubsection{Synthetic Megha-Tropiques observations}

The RTTOV fast radiative transfer model, version 9.3 (Radiative Transfer for Television and Infrared Observation Satellite Operational Vertical Sounder, Matricardi et al., 2004), is used to simulate SAPHIR and MADRAS BTs from the 22level thermodynamic profiles described above. Because the surface emissivity contributes strongly to the upwelling radiation in the microwave domain (Ulaby et al., 1981; Bennartz and Bauer, 2003) its implementation is important for realistic radiative transfer simulations. Indeed, the surface emissivity affects the observed microwave upwelling radiation in the two lower channels of SAPHIR $(183.31 \pm 6.8$ and $\pm 11 \mathrm{GHz}$, with a difference of BT of up to $5 \mathrm{~K}$ for some cases) and of all the nine channels of MADRAS. In RTTOV v9.3, the oceanic surface emissivities are computed with the FASTEM-3 surface model (fast emissivity model, Deblonde and English, 2001) using the $10 \mathrm{~m}$ wind speed. Here we use the wind extracted from a 18-year climatology from the ERA-Interim model covering the same period as the thermodynamic profiles (1990-2008). Over continental surfaces, the emissivity atlas of Prigent et al. (2006), elaborated from 10 years of Special Sensor Microwave Imager (SSM/I) observations, is preferred over the internal module of RTTOV. Finally, SAPHIR BTs are simulated only in the nadir geometry, whereas the simulations of MADRAS BTs are performed at the radiometer's constant viewing angle of $53.5^{\circ}$.

The simulations also make use of the instrumental noise to have a realistic base of work. The radiometric sensitivity is often considered as the instrumental noise since it gives the minimum variation in the measured upwelling radiation that a specific channel can detect (noise-equivalent $\Delta T: \mathrm{NE} \Delta T$, in $\mathrm{K}$ ). This noise may be considered as additive and modeled as realizations of a random variable following a normal distribution with a zero mean and a standard deviation equal to the NE $\Delta T$ value for each channel. The simulated data sets are re-built by aggregating 10 noisy samples for each original sample.

With the conclusion of MADRAS after almost 15 months of measurements, two configurations of the RH retrieval method have been considered: a SAPHIR-only scheme and 


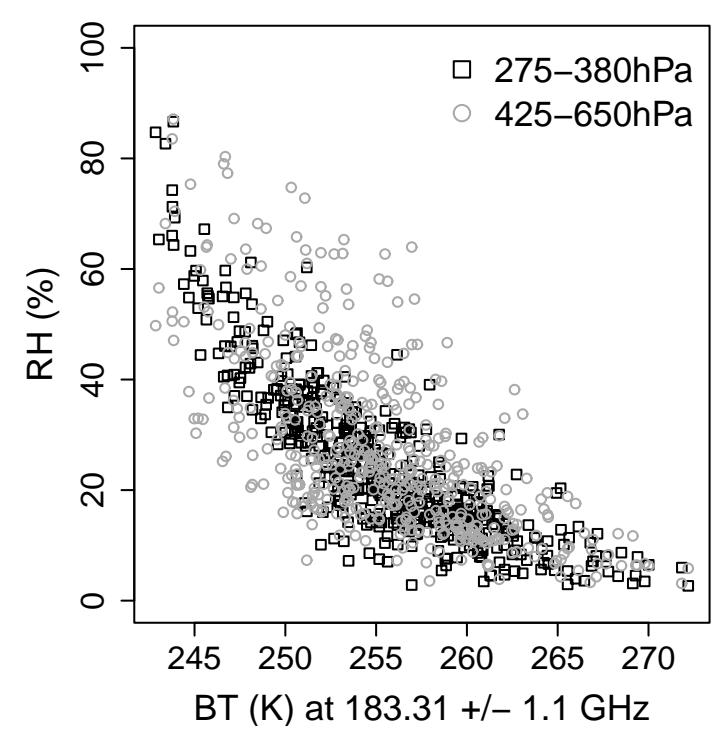

Figure 2. Relationship between the $\mathrm{RH}$ of two atmospheric layers (in \% RH) and the associated BT (in K) at $183.31 \pm 1.1 \mathrm{GHz}$ (2nd channel of SAPHIR). The RH of the $275-380 \mathrm{hPa}$ layer is represented with black squares, while the gray circles are for the $\mathrm{RH}$ of the $425-650 \mathrm{hPa}$ layer.

a SAPHIR-MADRAS scheme, the latter being associated to a selection of the optimal channels. For the former configurations all SAPHIR channels are used. For the latter configuration, a selection of the BTs is performed because the BTs that will be significantly relevant in the $\mathrm{RH}$ retrieval of a given layer will not necessarily be the same set when considering another layer. For this purpose the optimal subset of channels is determined thanks to the Gram-Schmidt orthogonalization (GSO) procedure (see Chen et al., 1989). Here, since the size of the whole input set (the BTs) does not exceed 15 elements, the GSO procedure is implemented according to a wrapper approach. This is performed for each atmospheric layer.

\section{Description of the non-linear models}

\subsection{General aspects}

To ensure the consistency between the mathematical descriptions of the three statistical models, the notation will be as follows: the estimation of the $\mathrm{RH}^{i}$ of a specific layer $i$ $(i \in[1 ; 7])$, namely the output, is performed from a vector of BTs, the inputs, which is a $p$-dimensional covariate noted $\boldsymbol{B} \boldsymbol{T}(p \in[1 ; 15])$. Thus, for each layer $i$ the training data set is made of $(p+1)$-tuples $\left\{\boldsymbol{B} \boldsymbol{T}_{k}, \mathrm{RH}_{k}^{i}\right\}_{k=1}^{N}$, where the cardinality of the set $N$ is 16310 (1631 profiles $\times 10$ noisy reproductions).

The GAM, MLP and LS-SVM models are built with three different statistical supervised learning techniques. Overall, the learning phase consists of using a set of training exam- ples to produce an inferred function. Each example is a pair made of an input vector $(\boldsymbol{B} \boldsymbol{T})$ and a desired output value $\left(\mathrm{RH}^{i}\right.$ of layer $\left.i\right)$, without other a priori information. The nonlinearity between the input vector $\boldsymbol{B T}$ and the $\mathrm{RH}^{i}$ is more or less strong depending on the channel of observation and the atmospheric layer (Soden and Bretherton, 1993; Stephens et al., 1996; Brogniez and Pierrehumbert, 2006; Brogniez et al., 2013). This is especially true for upper tropospheric channels, as illustrated on Fig. 2 for the BT of the $183.31 \pm 1.1 \mathrm{GHz}$ channel of SAPHIR and the $\mathrm{RH}^{3}$ and $\mathrm{RH}^{4}$ (taken from the synthetic base). Therefore the approach chosen is to adjust and optimize the $\boldsymbol{B} \boldsymbol{T}$-to- $\mathrm{RH}^{i}$ relationships separately for each of the seven layers.

The data set described in Sect. 2 is randomly divided into two subsets: a subset of $2 / 3$ of the $N$ samples $(\sim 11000$ samples) is dedicated to the training and to the validation of the models while the remaining $1 / 3$ forms the test set $(\sim 5000$ samples). Some parameters of the three modeling methods have to be adjusted and the selected models are those with the best generalization capabilities. These parameters are tuned to minimize the validation error which is an empirical estimation of the generalization error. Thus the selection of the models consists of the involvement of an efficient validation method. Various validation techniques exist in the literature (Hastie et al., 2009). The most popular techniques are probably the cross-validation method and the leave-one-out (LOO) technique, which are implemented according to the modeling method. Note that since the three modeling methods will be compared, we focus on efficient validation techniques and pay less attention to the computational burden they involve.

The input vector $\boldsymbol{B} \boldsymbol{T}$ is normalized (zero mean and unit variance). While such normalization does not affect the estimation provided by GAM (but only the relative weight of each predictor in the fit), the normalized input data set is the same for all models in order to simplify the process. A principal component analysis (PCA) is also implemented on the $\boldsymbol{B} \boldsymbol{T}$ to feed each statistical model with uncorrelated and linearly independent data. Indeed, the weighting functions of the six channels of SAPHIR slightly overlap each other to cover the entire absorption line. As a result, while each channel receives mainly the radiation emitted by a given layer of the atmosphere, contributions from layers above and below are not negligible, yielding to some interdependencies between the channels. Finally, in order to account for the known exponential relationship between the BT in the $183.31 \mathrm{GHz}$ line and the atmospheric RH (for instance at $183.31 \pm 1.0 \mathrm{GHz}$, see Spencer and Braswell, 1997, and Buehler and John, 2004), the use of the exponential function is also considered, which has also the advantage to ensure the retrieval of positive values. The effect of the PCA and of the exponential function have been evaluated for each statistical model for each layer $i$. The configuration with the smallest validation error was selected. 


\subsection{Generalized additive model}

GAMs have recently started to be used in environmental studies as a surrogate to traditional MLP thanks to their ability to model nonlinear behaviors while providing a control of the physical content of the statistical relationships (Wood, 2006). Therefore, among the recent works, one can cite the use of GAM to perform a statistical downscaling of precipitations (e.g., Beckmann and Buishand, 2002; Vrac et al., 2007), to analyze time series (Davis et al., 1998; Mestre and Hallegatte, 2009; Underwood, 2009) and more recently to solve inverse problems (e.g., Brogniez et al., 2013). A reasonable number of papers provide in-depth descriptions of the GAM algorithm, and one can refer to Wood (2006) for a detailed presentation of the background and the implementation issues of such model. We provide here only briefly its main characteristics. A GAM infers the possible nonlinear effect of a set of $p$ predictors $\left(\mathrm{BT}_{1}, \ldots, \mathrm{BT}_{p}\right)$ to the expectation of the predicant $\mathrm{RH}^{i}$. It is expressed as followed:

$g\left(\mathbf{E}\left(\widehat{\mathrm{RH}}^{i} \mid \boldsymbol{B} \boldsymbol{T}\right)\right)=\epsilon^{i}+f_{1}\left(\mathrm{BT}_{1}\right)+f_{2}\left(\mathrm{BT}_{2}\right)+\ldots+f_{p}\left(\mathrm{BT}_{p}\right)$,

where $g$ is a linearizing link function between the expectation of $\widehat{\mathrm{RH}}^{i}$ given $\boldsymbol{B} \boldsymbol{T}$ and the additive predictors $f_{j}\left(\mathrm{BT}_{j}\right)$, which are smooth and generally non-parametric functions of the covariates $\mathrm{BT}_{1}, \ldots, \mathrm{BT}_{p}$. Finally $\epsilon^{i}$ is the residual that follows a normal distribution. Here, penalized regression cubic splines are used as the smoothing functions and are estimated independently of the other covariates using the "backfitting algorithm" (Hastie and Tibshirani, 1990). Part of the model-fitting process is to determine the appropriate degree of smoothness, which is done through a penalty term in the model likelihood, controlled by a smoothing parameter $\lambda . \lambda$ determines the trade off between the goodness of fit $(\lambda \rightarrow 0$, gives a wiggly function) of the model and its smoothness $(\lambda \rightarrow \infty)$.

Part of the GAM fitting process is to choose the appropriate degree of smoothness of the regression splines. The smoothing parameter $\lambda$ is adjusted to minimize the generalized cross validation score (GCV). One can refer to Wood (2004) and Wood (2006) for more details on the training algorithm.

\subsection{Multilayer perceptron algorithm}

An artificial neural network is an interconnection of simple computational elements (nodes or neurons) using functions that are usually non-linear, monotonically increasing and differentiable (Haykin, 1994). The multilayer perceptron (MLP) algorithm belongs to the family of artificial neural networks (Rumelhart et al., 1986). MLPs are attractive candidates thanks to various well known properties. For instance, an MLP is a universal function approximator and thus can represent any arbitrary functions (Bishop, 1995), so they are widely used for the approximation of non-linear transfer functions. Moreover MLPs have been shown to be able to deal with noisy data. In our case, defining the architecture of the MLP consists of (i) selecting the relevant input variables and (ii) setting the number of neurons in the hidden layer. A fixed architecture defines a function family $F(\cdot)$, in which we seek the best function allowing us to invert BTs. It is possible to express this MLP model in a mathematical way as

$\widehat{\mathrm{RH}}^{i}=F(\mathbf{W}, \boldsymbol{B} \boldsymbol{T})$,

where $F(\cdot)$ and $\mathbf{W}$ correspond respectively to the transfer function and the synaptic weights matrix of the model. The main critical point with the MLP method is the way to choose the optimal architecture and to adjust the corresponding internal parameters (the weights). These parameters are determined so as to minimize the mean quadratic error computed on the training data set. As our goal is to create a nonlinear model with good generalization capabilities, the problem of overfitting must be considered. To avoid overfitting, the LOO validation method is implemented to check the possible overfitting and to optimally select model parameters such as to minimize the validation error.

\subsection{Least squares support vector machine}

SVMs are kernel methods (Scholkopf and Smola, 2002). They are attractive candidates for nonlinear modeling from data. Thanks to various desirable properties, they have the ability to build models with high generalization capabilities by avoiding overfitting and controlling model complexity. A least squares formulation of SVM called LS-SVM was proposed to make the SVM approach for modeling more generally applicable, such as for dynamic modeling $(\mathrm{Qu}, 2009)$ or for implementing sophisticated validation techniques (Cawley and Talbot, 2007). The SVM technique and its derived formulations have found applications in atmospheric sciences, such as in statistical downscaling of precipitation (Tripathi et al., 2006; Anandhi et al., 2008), in regression problems (Sun et al., 2005) or in classification from remote sensing measurements (Lee et al., 2004).

The LS-SVM training procedure consists of estimating the set of adjustable parameters $\mathbf{w}$ and $b$ by the minimization of the cost function:

$J(w, e)=\frac{1}{2} \mathbf{w}^{T} w+\frac{1}{2} C \sum_{k=1}^{N} e_{k}^{2}$,

with $e_{k}$ the prediction error for example $k$ and $N$ the size of the training set. $C$ is an hyperparameter that controls the tradeoff between the prediction error and the regularization. This optimization problem can be cast into a dual form with unknown parameters $\boldsymbol{\alpha}$ and $b, \boldsymbol{\alpha}$ being the vector of the Lagrange multipliers. Thus, the parameters can be computed by resolving a set of $(N+1)$ linear equations.

Since LS-SVM models are linear in their parameters models, the solution of the training phase is unique and can be 
computed straightforwardly, using the set of $(N+1)$ linear equations as stated above. Here the validation error is estimated using the virtual LOO (or VLOO) method. This method, first proposed for linear models (Belsley et al., 1980) and later extended to nonlinear models (Laurent and Cook, 1993), allows to estimate the validation error by performing one training involving the whole available data. This estimation is exact when dealing with linear-in-their-parameters models, such as LS-SVM models, while it remains an approximation for models which are nonlinear with respect to their parameters. More recently, a framework described by (Cawley and Talbot, 2007) implements the VLOO method for LS-SVM models. This method gives a fast and exact estimation of the validation error, which is a great benefit for reducing the computational burden involved by other validation techniques such as the cross validation method (Hastie et al., 2009).

\section{Performance over the synthetic data set}

The retrievals of layer-averaged RH profiles provided by GAM, MLP and LS-SVM are compared for the two schemes. The following criteria are computed over the test set $(\sim 5000$ samples) for each atmospheric layer $i$ : the mean error (referred to as the "bias"), the standard deviation of the error (SD) and the Pearson's correlation coefficient $(R)$ between the estimated $\widehat{\mathrm{RH}}$ and the reference $\mathrm{RH}$, using the variancecovariance matrix (cov):

$$
\begin{aligned}
l l \mathrm{SD}^{i} & =\sqrt{\frac{1}{N} \sum_{k=1}^{N}\left(\mathrm{RH}_{k}^{i}-\widehat{\mathrm{RH}}_{k}^{i}\right)^{2}} \\
\operatorname{bias}^{i} & =\sum_{k=1}^{N}\left(\mathrm{RH}_{k}^{i}-\widehat{\mathrm{RH}}_{k}^{i}\right) \\
R^{i} & =\frac{\operatorname{cov}\left(\mathrm{RH}^{i}, \widehat{\mathrm{RH}}^{i}\right)}{\sqrt{\mathrm{SD}^{2}\left(\mathrm{RH}^{i}\right) \cdot \mathrm{SD}^{2}\left(\widehat{\mathrm{RH}}^{i}\right)}} .
\end{aligned}
$$

Moreover, the notation \% RH will be used to make easier the discussion between relative units (in \%) and RH units (in $\% \mathrm{RH})$. The size of the test set allows to consider that all the results are significant at the $99.9 \%$ level of confidence.

\subsection{On the optimization of the models}

As mentioned in Sect. 2.2.3, it is important to underline that the optimized models are different for each atmospheric layer. Indeed, in the case of the SAPHIR-MADRAS scheme a selection of the relevant channels is performed using the GSO procedure. The GSO procedure helps to reduce the complexity of the algorithms by reducing the number of inputs of the available set of data. It is implemented in the present case with a reasonable threshold of $10 \%$ on the variation of the variance. This means that the inputs that enhance the error variance less than $10 \%$ are considered as irrelevant. Of course the same inputs could be used for the different models with small deterioration. For example, for the layer $4(425-650 \mathrm{hPa})$, a sensitivity analysis has shown that, when using GAM, the best set of inputs is $\{\mathrm{S} 3, \mathrm{~S} 4, \mathrm{~S} 5$, S6, M3, M4 3 and if M9 is added, the SD decreases from 4 to $3.8 \% \mathrm{RH}$. When the RH retrieval is based on the MLP approach, the SD increases from 2.8 to $3 \% \mathrm{RH}$. In these two cases the difference is relatively small. In fact, an indepth study of the relevancy of the channels reveals that the selected inputs are only weakly dependent on the retrieval model but are highly dependent on the atmospheric layer.

For the SAPHIR-only scheme, all channels are used.

An impact study of the pre-processing of the data on the accuracy of RH retrieval shows that, whatever the atmospheric layer or algorithm considered, the improvement obtained with PCA is negligible ( $<3 \%$ of the error variance). The use of uncorrelated inputs is thus not necessarily required for the considered models. Finally, the linearization of the problem with the exponential function is beneficial only for the MLP: in this case it leads to a decrease of the error variance of about $50 \%$, while no significant improvement is observed for LS-SVM and GAM $(<3 \%$ of the error variance).

\subsection{Performance of GAM against the two other models}

From here on, noise-free BTs are considered in order to only assess the statistical approaches. The radiometric noise of the two instruments are implemented for the evaluation of the retrieval of RH with profiles considered as reference profiles. Vertical profiles of mean biases, SD and $R$ between the observed RH and the estimated RH are presented on Fig. 3. At first sight, the analysis of one layer at a time clearly shows that the overall quality of the retrieval is layer-dependent, meaning that it is strongly constrained by the physical limits of the inverse problem. Thus, the layers covering the free troposphere (layers 2 to 6 ) are quite well modeled, with small SD reaching values between $2.6 \% \mathrm{RH}$ and $7.8 \% \mathrm{RH}$, and are characterized by a small scatter, with $R$ lying in the $0.85-$ 0.97 interval. The combined use of SAPHIR and MADRAS BTs is enough to explain more than $70 \%$ of the variability of the RH at these layers. The retrieval of the RH of the extreme layers (layer 1 for the top of the atmosphere, layer 7 for the surface) seems more delicate and is clearly limited by the inputs at hand: as illustrated on Fig. 1a, the six channels of SAPHIR observe the emitted radiation grossly between 150 and $850 \mathrm{hPa}$, and although MADRAS brings some additional relevant measurements, other information such as the surface emissivity might contribute significantly to better constrain the retrieval near the surface.

The LS-SVM technique provides overall the best results, with the highest correlation coefficients and the lowest variance for five layers over the seven considered in this study. In fact, theoretically, these three learning methods are equivalent, but the conditions of their implementation are 
Table 2. Mean bias (in $\% \mathrm{RH})$, standard deviation (SD, in $\% \mathrm{RH})$ and correlation coefficient $(R)$ for the seven layers, and defined between the observed RH and the estimated RH. The estimated RH is obtained using the GAM approach from the two configurations: SAPHIRMADRAS joint measurements and SAPHIR-only measurements. For the SAPHIR-MADRAS configuration, the relevant channels selected using the GSO procedure are listed using the labels $\mathrm{S}_{i}$ and $\mathrm{M}_{j}$ indicated in Table 1.

\begin{tabular}{|c|c|c|c|c|}
\hline Layer \# & Scores & $\begin{array}{r}\text { SAPHIR \& } \\
\text { MADRAS } \\
\text { Relevant channels }\end{array}$ & & $\begin{array}{r}\text { SAPHIR } \\
\text { All channels }\end{array}$ \\
\hline $\begin{array}{l}\# 1 \\
(85-100 \mathrm{hPa})\end{array}$ & $\begin{array}{c}\text { bias }(\%) \\
\operatorname{SD}(\%) \\
R\end{array}$ & $\begin{array}{c}\mathrm{S} 1, \mathrm{~S} 2, \mathrm{~S} 3, \mathrm{~S} 5 \\
\mathrm{M} 1, \mathrm{M} 2, \mathrm{M} 3, \mathrm{M} 4, \mathrm{M} 5, \\
\mathrm{M} 6, \mathrm{M} 7, \mathrm{M} 8, \mathrm{M} 9\end{array}$ & $\begin{array}{l}1.98 \\
8.92 \\
0.67\end{array}$ & $\begin{array}{l}2.36 \\
9.91 \\
0.57\end{array}$ \\
\hline $\begin{array}{l}\# 2 \\
(130-250 \mathrm{hPa})\end{array}$ & $\begin{array}{c}\text { bias }(\%) \\
\mathrm{SD}(\%) \\
R\end{array}$ & $\begin{array}{c}\mathrm{S} 1, \mathrm{~S} 2, \mathrm{~S} 3 \\
\mathrm{M} 1, \mathrm{M} 2, \mathrm{M} 3, \mathrm{M} 4 \\
\mathrm{M} 5, \mathrm{M} 6, \mathrm{M} 7\end{array}$ & $\begin{array}{c}-0.01 \\
5.96 \\
0.92\end{array}$ & $\begin{array}{r}-0.09 \\
6.02 \\
0.91\end{array}$ \\
\hline $\begin{array}{l}\text { \# } 3 \\
(275-380 \mathrm{hPa})\end{array}$ & $\begin{array}{c}\text { bias }(\%) \\
\operatorname{SD}(\%) \\
R\end{array}$ & $\begin{array}{l}\mathrm{S} 1, \mathrm{~S} 2, \mathrm{~S} 3, \mathrm{~S} 4, \mathrm{~S} 5, \mathrm{~S} 6 \\
\mathrm{M} 1, \mathrm{M} 2, \mathrm{M} 3, \mathrm{M} 5, \mathrm{M} 6\end{array}$ & $\begin{array}{l}0.48 \\
3.67 \\
0.95\end{array}$ & $\begin{array}{l}0.48 \\
3.79 \\
0.94\end{array}$ \\
\hline $\begin{array}{l}\# 4 \\
(425-650 \mathrm{hPa})\end{array}$ & $\begin{array}{c}\text { bias }(\%) \\
\operatorname{SD}(\%) \\
R\end{array}$ & $\begin{array}{c}\mathrm{S} 1, \mathrm{~S} 3, \mathrm{~S} 4 \\
\mathrm{M} 1, \mathrm{M} 3, \mathrm{M} 5, \mathrm{M} 7\end{array}$ & $\begin{array}{l}0.45 \\
3.56 \\
0.97\end{array}$ & $\begin{array}{l}0.08 \\
4.72 \\
0.95\end{array}$ \\
\hline $\begin{array}{l}\text { \# } 5 \\
(725-850 \mathrm{hPa})\end{array}$ & $\begin{array}{c}\text { bias }(\%) \\
\operatorname{SD}(\%) \\
R\end{array}$ & $\begin{array}{c}\text { S1, S3, S5, S6 } \\
\text { M3, M4, M7, M9 }\end{array}$ & $\begin{array}{l}0.95 \\
8.55 \\
0.91\end{array}$ & $\begin{array}{r}2.69 \\
11.68 \\
0.83\end{array}$ \\
\hline $\begin{array}{l}\text { \# } 6 \\
(900-955 \mathrm{hPa})\end{array}$ & $\begin{array}{c}\text { bias }(\%) \\
\operatorname{SD}(\%) \\
R\end{array}$ & $\begin{array}{c}\mathrm{S} 1, \mathrm{~S} 3, \mathrm{~S} 4, \mathrm{~S} 5, \mathrm{~S} 6 \\
\mathrm{M} 1, \mathrm{M} 3, \mathrm{M} 4, \mathrm{M} 5, \mathrm{M} 6, \\
\text { M7, M8, M9 }\end{array}$ & $\begin{array}{l}0.11 \\
6.72 \\
0.91\end{array}$ & $\begin{array}{r}-1.53 \\
11.65 \\
0.70\end{array}$ \\
\hline $\begin{array}{l}\# 7 \\
(1013 \mathrm{hPa})\end{array}$ & $\begin{array}{c}\text { bias }(\%) \\
\operatorname{SD}(\%) \\
R\end{array}$ & $\begin{array}{c}\mathrm{S} 1, \mathrm{~S} 2, \mathrm{~S} 3, \mathrm{~S} 4, \mathrm{~S} 5, \mathrm{~S} 6 \\
\mathrm{M} 1, \mathrm{M} 2, \mathrm{M} 3, \mathrm{M} 4, \mathrm{M} 5 \\
\mathrm{M} 6, \mathrm{M} 7, \mathrm{M} 8, \mathrm{M} 9\end{array}$ & $\begin{array}{l}0.36 \\
8.69 \\
0.54\end{array}$ & $\begin{array}{r}-0.02 \\
9.67 \\
0.34\end{array}$ \\
\hline
\end{tabular}
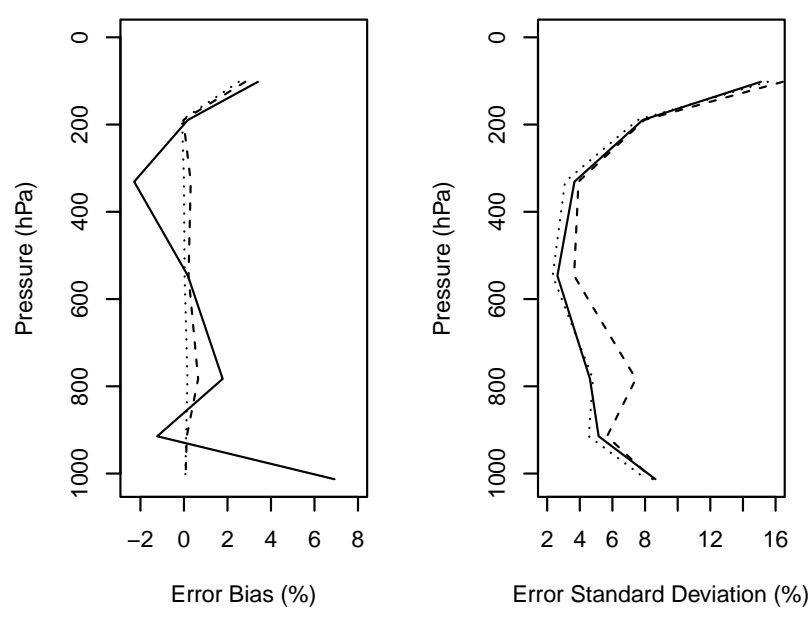

Figure 3. Vertical profiles of $R$ (left), biases (center, in \%RH) and $\mathrm{SD}$ (right, in \%RH) for the MLP (solid line), the GAM (dashed line) and the LS-SVM (dotted line) models, trained on noise-free SAPHIR and MADRAS data. somewhat different. First, since the LS-SVM are linear-intheir-parameters models, an exact validation method was implemented. The resulting procedure of selection of the relevant inputs is quite efficient. In addition, MLP models are nonlinear with respect to the adjusted parameters, and their training amounts to a nonlinear optimization. Several trainings with different initializations must be performed with no guarantee to achieve the best generalization capability given a network architecture. From this point of view, the LS-SVM approach is thus more successful. Finally, concerning the GAM approach, the smoothing splines used guarantee a nonlinear behavior, continuity and smoothness which are important characteristics in a learning algorithm. Another convenient characteristic for splines is that they are monotonic: the back-propagation algorithm can estimate parametric and non-parametric components of the model simultaneously.

The three methods perform equivalently: $R$ and SD are very close to each other. The MLP approach provides slightly more biased estimations of the RH throughout the troposphere while the GAM and LS-SVM methods are centered. This distinction is more pronounced for the surface layer with retrievals of RH characterized with a $6.9 \% \mathrm{RH}$ bias 
when using the MLP, whereas the bias is $0.06-0.07 \% \mathrm{RH}$ with GAM and LS-SVM. A sample of layer-averaged profiles is presented on Fig. 4, with the observed relative humidity and the three estimations using the three approaches. As discussed above the top layer is the less well retrieved from the set of BTs, whatever the approach, while the midtropospheric layers ( 3 to 6 , i.e., 350 down to $950 \mathrm{hPa}$ ) are pretty well estimated.

The errors obtained from the GAM estimation are projected on the $10 \times 10$ Kohonen maps that were obtained during the stage of clustering of the atmospheric layers (Sect. 2.2.2) and give a structural view of the errors. The projections are shown on Fig. 5. This allows to analyze the retrieval errors with respect to the clusters of RH revealed by the maps, and allow for a deeper analysis related to meteorological situations than the global biases and SD. A pattern of a large bias $(\sim 44 \% \mathrm{RH})$ clearly stands out of the map of layer 1 (near tropopause), and this bias is associated to the neurons related to a moist structure at this top layer. This suggests that GAM has difficulties when dealing with a moist upper troposphere, that could be due to an underrepresentation in the training set. A similar statement can be made for the 6th layer, with the neurons associated to the largest bias in the upper left corner (negative in this case) being this associated to the more dry neurons of this layer. There is no clear pattern standing out of the remaining layers, even for the surface layer, meaning that the errors are uniformly distributed.

\subsection{Performance for the two instrumental schemes}

In the following, noisy BTs are used in order to discuss the results over the realistic instrumental configurations. Two GAMs are optimized for each atmospheric layer, one for each instrumental scheme: a SAPHIR-MADRAS scheme and a SAPHIR-only scheme. The evaluations over the validation set are summarized on Table 2, with biases, SD and $R$. An illustration of the scatter is given with Fig. 6 for two atmospheric layers: layer $4(\sim 425-650 \mathrm{hPa})$ and layer 6 $(\sim 900-955 \mathrm{hPa})$. These statistics allow for a discussion on the influence of MADRAS BTs on the quality of retrieval of the RH. MADRAS channels are an asset for the estimation of the RH profile since their use reduce the scatter (improvement of $R$ and reduction of SD). The pattern of scatter follows the distribution of the weighting functions of SAPHIR: the best estimations are obtained for the mid-tropospheric layers ( $R=0.83$ to 0.97 , over layers 2 to 5 ) where the functions strongly overlap, and the quality of the estimations decrease towards the edges. One can also note that the retrieval model of the 7th layer uses all 15 BTs of the microwave payload, but this does not allow for a robust estimation of the $\mathrm{RH}$ ( $R=0.54$, corresponding to a $R^{2}$ value of 0.29 ). An estimation of the RH profile down to $955 \mathrm{hPa}$ seems reasonable if no other constraint is added to the model.
When the SAPHIR-only scheme is used, such a statement can be extended to the top layer $\left(R=0.57, R^{2}=32\right)$, thus limiting the estimation of RH from layer 2 to layer 6 . For these atmospheric layers, the biases are small and range between 2.69 and $-1.53 \%$ RH. The impact of MADRAS BTs on the retrieval of RH is important to keep in mind when specific analysis of temporal and spatial variations of the RH field will be performed over the MT (Megha-Tropiques) lifetime.

\section{Application to Megha-Tropiques measurements}

\subsection{Some considerations on the Megha-Tropiques observations}

As other similar radiometers with varying viewing geometries, SAPHIR observations are subject to the so-called "limb effect", described for instance in Goldberg et al. (2000). This means that, at SAPHIR frequencies, the pixels on the edge of the swath have BTs artificially lower than the pixels located in the center, the atmosphere of the former having a larger optical depth than the latter. For the same thermodynamical profile, this limb effect yields to shift upward the sounding altitude of the outermost pixels. Of course this needs to be taken into account in any retrieval processes (e.g., Karbou et al., 2005; Buehler et al., 2004). Possibilities are (i) to have one dedicated model per viewing angle (as done by Buehler and John, 2004), (ii) to include explicitly the viewing angle in the retrieval method traditionally done in iterative schemes (see Soden and Bretherton, 1993; Liu and Weng, 2005), or (iii) to apply a correction that brings all the viewing angles to an equivalent nadir position, before the retrieval itself (Brogniez and Pierrehumbert, 2006). Here, the GAMs have been optimized using the nominal viewing angle of MADRAS $\left(53.5^{\circ}\right)$ and limited to the nadir geometry of SAPHIR. In fact, the observed relationship between the BT and the viewing angle can be accurately approximated by a multi-variate linear function, as noticed by Goldberg et al. (2000) and Buehler et al. (2004). Knowing the means and variances of this relationship for each angle is enough to assimilate this function in the normalization method, which is based on standard scores. These have been computed every $2^{\circ}$ from nadir to $52^{\circ}$ (the maximum viewing angle of SAPHIR is $50.7^{\circ}$ ) using the training database.

\subsection{Comparison to radiosonde measurements: the CINDY/DYNAMO/AMIE data set}

Observed RH profiles gathered from the CINDY/DYNAMO/AMIE international field experiment are used to evaluate the estimated RH profiles. With the 1st orbit of Megha-Tropiques executed on 13 October 2011, this large scale campaign is ideal to perform such an exercise. It took place over the October 2011-March 2012 period in the Indian Ocean and was dedicated to better understand the 

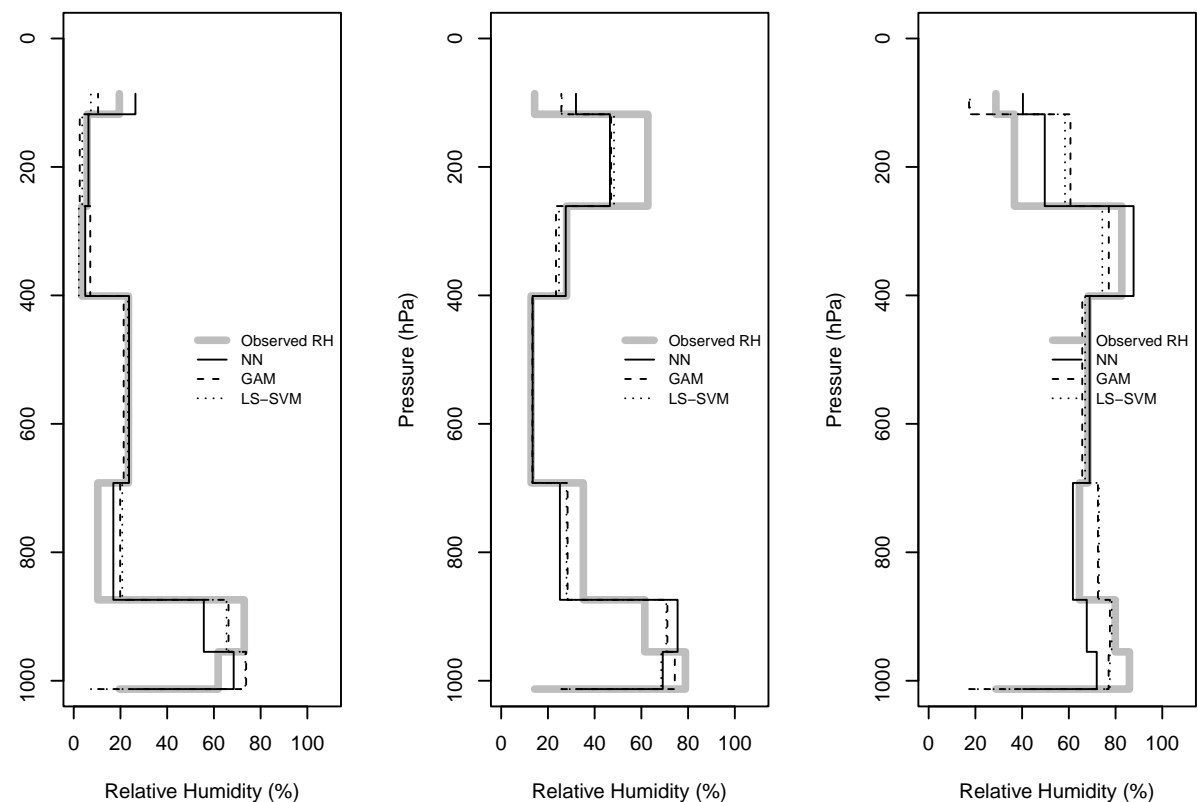

Figure 4. Examples of three estimations of RH profiles (in \% RH) extracted from the database using the SAPHIR-MADRAS configuration. The observed profile is the thick gray line and the three estimations (plain, dashed, dots, respectively, for MLP, GAM and LS-SVM) are in black.
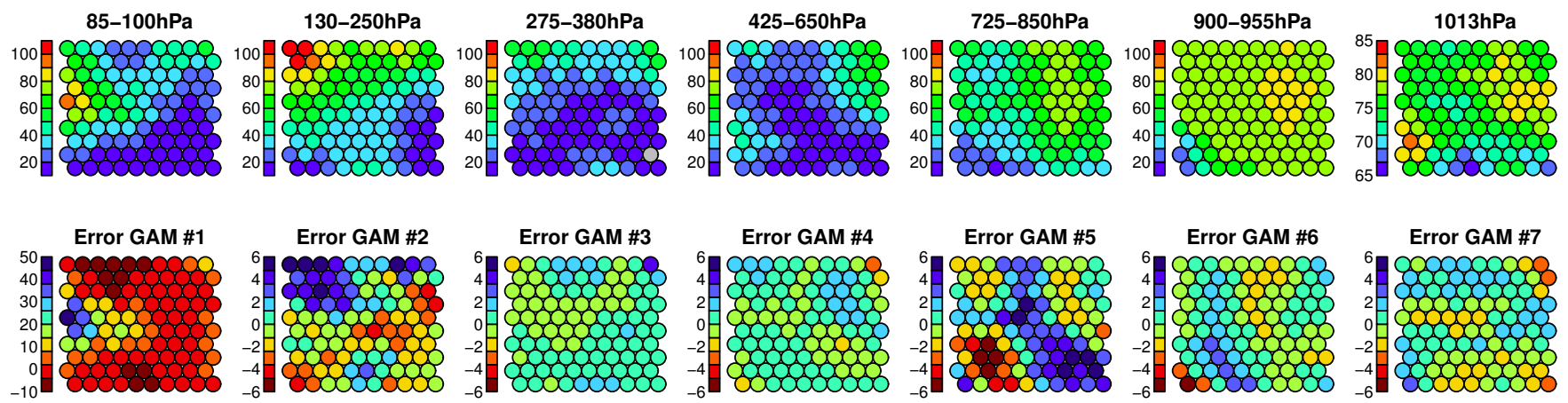

Figure 5. RH and the associated errors (both in $\% \mathrm{RH}$ ) projected on the $10 \times 10$-neuron self-organizing maps obtained from the step of clustering of the original RH profiles (see Sect. 2.1): the upper row shows the mean RH for the seven layers, and the lower row shows the errors of estimation using GAMs. Note that the color scales of the maps representing the $1013 \mathrm{hPa}$ layer and the error estimated for layer 1 are adjusted.

processes involved in the initiation of the Madden-Julian Oscillation and to improve its simulation and prediction (Cooperative Indian Ocean Experiment on Intraseasonal Variability in the Year 2011/Dynamics of the Madden-Julian Oscillation/ARM Madden-Julian Oscillation Investigation Experiment, hereafter C/D/A). Measurements related to the atmospheric and oceanic states have been collected from radars, microphysics probes, a mooring network and an upper air sounding network. One can refer to Clain et al. (2015) for a discussion on the quality of the RH profiles and their use in the context of the evaluation of SAPHIR measurements. Here we focus on the oceanic sites and on the October-December 2011 period to evaluate the RH esti- mations; over that period, MADRAS performed optimally. Clain et al. (2015) found a systematic bias in the BT space that increases with the distance of the observing channel from the central frequency. Such biases are eliminated by the normalization procedure of the retrieval scheme. Overall, among the 10000 high-resolution soundings collected during the campaign (Ciesielski et al., 2015), only about 50 profiles match to our collocation criteria: a $\Delta t \leq \pm 45 \mathrm{~min}$ and a $\Delta x \leq 50 \mathrm{~km}$.

The restriction of the training of the GAMs to clear-sky conditions requires a cloud mask. Therefore, cloud-free cases are detected from the radiosounding record itself (RH limited to $100 \% \mathrm{RH}$ ) and are associated to the Hong et al. (2005) 

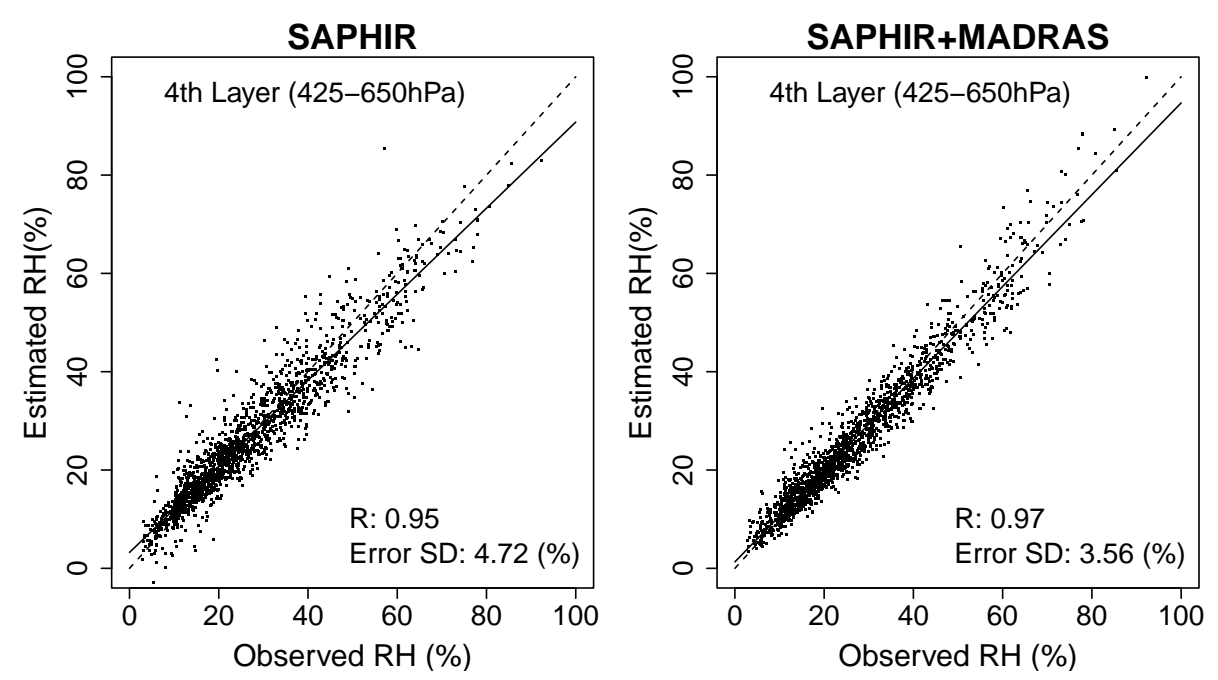

Figure 6. Scatter-plots of the observed RH versus the estimated RH (in \% RH) for layer 4 (top row) and layer 6 (bottom row). The estimations are done using GAMs trained from SAPHIR-only BTs (left-hand side column) and from SAPHIR and MADRAS BTs (right-hand side column). The dashed line is $y=x$ line and the solid line represents the linear regression. The correlation coefficient $(R)$ and the standard deviation of the error (SD) are provided within each panel.

method to detect the precipitating scene (i.e., the convective overshootings: it is a threshold method based on the depression induced by the scattering of the microwave radiation by the precipitating particles) from the SAPHIR observations. One point of concern here is the availability of the MeghaTropiques archive over this period which is not $100 \%$, with a lower availability for MADRAS. The completion of this archive until the date of launch is still a major point of concern for the two space agencies CNES and ISRO, in order to maximize the size of the MADRAS record.

For each of the seven layers, the observed RH is defined by the mean of the measurements that fit into the pressure boundaries, assuming that this mean will be representative of the layer. This assumption is very simple, especially since the tropospheric RH is characterized by strong vertical gradients induced by complex transport and thermodynamic processes (e.g., Pierrehumbert et al., 2007; Sherwood et al., 2010). However, a comparison (not shown) between such a smooth mean and a discrete mean as defined from the training profiles show no systematic differences. Figure 7 shows the comparison between the observed and estimated RH using profiles of $R$ and biases, for the two instrumental configurations. Figure 7 summarizes the results. Since the sample size is quite small $(N-2=48$ degrees of freedom), a Student $t$ test (Student, 1908) is performed to test the independence of the samples, assuming that they follow Gaussian distributions. The $99.9 \%$ level of confidence is indicated on Fig. 7 and $t$ values below this level are not given. Box-and-whiskers diagrams are used to represent the distributions of the differences and show the similarity/differences of the estimations when using both SAPHIR and MADRAS or only SAPHIR. As expected from the syn- thetic data analysis, the mid-tropospheric layers 2 to 5 are very well retrieved, with quite good correlations (0.6-0.92) when SAPHIR and MADRAS are combined. Additional analyses show that the SD of the differences reach a maximum of $10 \%$ RH (layer 4). The removal of MADRAS clearly affects the estimation of RH for most layers, while for layer 3 there is no significant effect. This is expected from the distribution of the weighting functions that present a large overlap around $300 \mathrm{hPa}$ (see also Fig. 1). Our results are consistent with the findings of Venkat Ratnam et al. (2013) dedicated to the evaluation of the $\mathrm{RH}$ profile retrieval designed by the Indian team involved in the Megha-Tropiques mission. The layer-averaged relative humidity (LARH) retrieval technique (Gohil et al., 2013) differs from the present approach by its dependence on outputs from the National Center for Environmental Prediction/National Center for Atmospheric Research (NCEP/NCAR) re-analyses. This explains the relatively closer pattern of the LARH estimated from SAPHIR to the NCEP/NCAR RH profiles than to other models (e.g., ERA-Interim), as found by Venkat Ratnam et al. (2013).

\subsection{Land surfaces}

The approach has been adapted to continental cases, where the influence of the surface emissivity on the measured brightness temperature at the top of the atmosphere needs to be taken into account (Karbou et al., 2005), even for SAPHIR channels. Moradi et al. (2013) have shown that for relatively humid columns, defined with a proper filter on the precipitable water vapor (PWV) given by radiosoundings, AMSU-B water vapor channels (similar to channels S2, S3 and S5 of SAPHIR) are barely sensitive to the surface. 

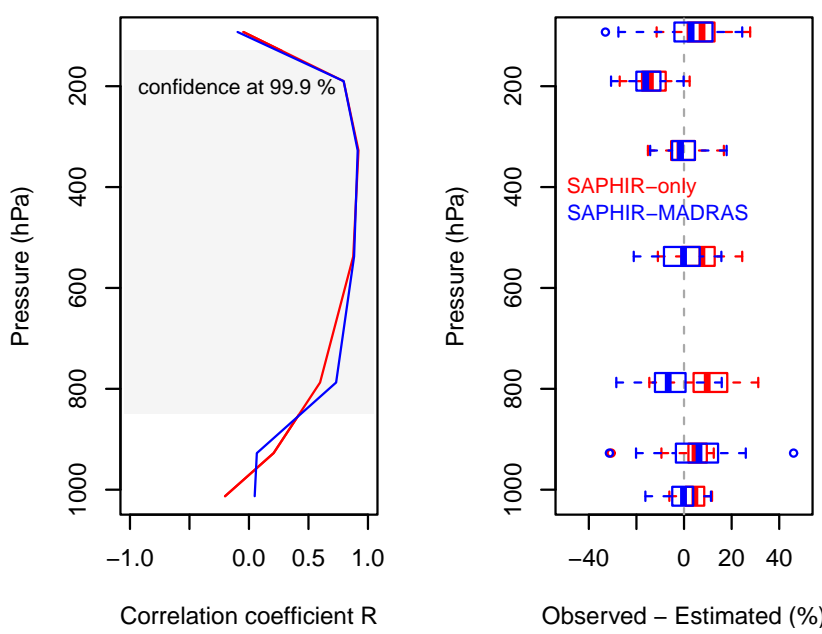

Figure 7. Vertical profiles of $R$ (left) and differences (right, in $\% \mathrm{RH}$ ) for the SAPHIR-only (red) and the SAPHIR-MADRAS (blue) retrievals, computed over the subset of 50 radiosonde $\mathrm{RH}$ profiles from the CINDY/DYNAMO/AMIE campaign. For the profiles of the differences between the observed and estimated $\mathrm{RH}$, the box and whiskers diagram indicates for each layer the median (the central vertical line) and the lower and upper quartiles (left and right edges of the box). The whiskers indicate the lower and upper limits of the distribution within 1.5 times the interquartile range from the lower and upper quartiles, respectively.

The emission by the surface affects the measured BT in the $183.31 \pm 7.0 \mathrm{GHz}$ (equivalent to channel S5) when the PWV is lower than $30 \mathrm{~kg} \mathrm{~m}^{-2}$. The Moradi et al. (2013) study focuses on polar atmospheres, and AMSU-B channels are much less affected by the surface when observing tropical situations (Aires et al., 2011). However, to limit the errors introduced by a possible contribution of the surface emissivity, the consideration of realistic surface emissivity is an asset for the definition of a realistic training set. In the current study, we use the emissivity atlas of Prigent et al. (2006) as an additional input of the radiative transfer model for the simulation of the BTs. A GAM is trained for each layer following the same method than for the oceanic conditions.

Comparisons (not shown) to radiosoundings launched from a continental site in Ouagadougou, Burkina Faso (a dedicated field campaign during the summer 2012) reveal similar performance in the mid-tropospheric layers, the surface layers being slightly better estimated.

\subsection{Insight of large scale structures}

Figure 8 shows an example of $\mathrm{RH}$ estimation using the SAPHIR-only scheme, for the 4th atmospheric layer (425$650 \mathrm{hPa}$ ) observed on 14 November 2011 (observing time 17:00-18:55 UT). The RH of ERA-Interim of the same date at 18:00 UT is also presented. The large-scale patterns are clearly identical in the two maps, such as the large dry area over West Africa, the moist and thin filamentary structure
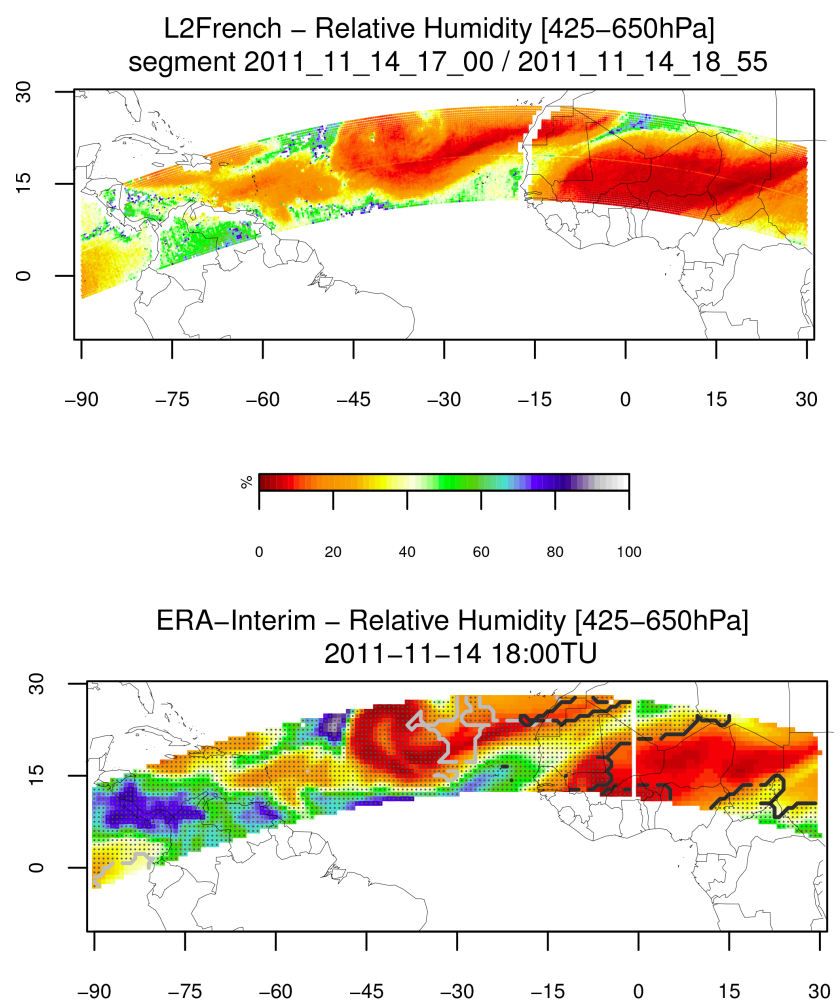

Figure 8. Relative humidity (in \%) of the layer 400-600 hPa as estimated from Megha-Tropiques/SAPHIR measurements (top) and by the ERA-Interim reanalysis (bottom) for 14 November 2011. For the map of ERA-Interim RH, the black contour delineates the clear sky and the grey contour delineates the areas with low-level clouds, while the dotted areas are covered with high or mid-level clouds.

northwest of it, or the moist area over Central America. The amplitude of the two fields present some discrepancies, but is important to focus specifically on the cloud-free zones. The high and mid-level clouds in ERA-Interim are shaded in black while the low clouds are delimited by the grey contour. Over these areas the amplitudes are similar, with minima of $\mathrm{RH}$ around $10 \% \mathrm{RH}$. Note that no cloud-mask is yet available for the Megha-Tropiques observations and a current effort is on the use of the cloud mask and cloud classification developed by the SAFNWC (Satellite Application Facility of EUMETSAT) and applied to the belt of geostationary satellites, adjusted to Megha-Tropiques.

\section{Conclusions}

Microwave observations from the SAPHIR and MADRAS microwave radiometers of the Megha-Tropiques satellite are used to retrieve seven-layer RH profiles. For this purpose, optimized GAMs were trained for each atmospheric layer over a realistic set of synthetic observations. This set is composed of 18 years of radiosonde profiles covering the tropical belt $\left( \pm 30^{\circ}\right)$, sampled from the ARSA database, used in 
combination with a radiative transfer model (RTTOV v9.3) to get the associated synthetic BTs. Our approach consists of using only the satellite measurements as inputs of the retrieval method. The training phase of the model considers implicitly the role of temperature, humidity and surface characteristics of the tropical atmosphere.

To assess the performance of GAM, two other algorithms based on supervised learning, namely a MLP and a LSSVM, have been also trained and optimized using adapted validation methods. To our knowledge, the LS-SVM modeling technique has never been applied for remote sensing retrievals, whereas it solves the major problem of local minima, a common pitfall when using neural networks (such as the MLP). While the three modeling methods come from different theoretical backgrounds, they achieve roughly the same performance, even though the LS-SVM approach provides roughly slightly better results. We assume that these improvements come from their built-in regularization mechanisms, but they are associated to a heavy computational burden that compromises their implementation when considering large data sets (such as satellite measurements).

The intercomparison of the three models points towards the definition of the problem given the inputs at hand. The combination of SAPHIR and MADRAS or the use of SAPHIR-only makes it possible to perform a robust estimation of RH in the $150-950 \mathrm{hPa}$ part of the troposphere with a small error (absolute maximum bias of $1.53 \% \mathrm{RH}$ ) and scatter (min correlation of 0.49 ). Near the tropopause and at the surface, the retrieval capacity is clearly constrained by the information content brought by the inputs, whatever the configuration. Of course, the use of a retrieval technique (e.g., neural network or 1-D-variational) using prior physical information should further improve the estimation: for instance, the surface layer should clearly benefit from prior knowledge of the surface temperature and total water vapor content. In fact, a comparison with existing works based on methods combining physical constraints with statistical tools (Kuo et al., 1994; Cabrera-Mercadier and Staelin, 1995; Rieder and Kirchengast, 1999; Liu and Weng, 2005; Aires et al., 2013) applied to on similar radiometers with less channels in the $183.31 \mathrm{GHz}$ line, such as AMSU-B or MHS, shows that the current approach gives similar performance (root mean square errors of about $10 \% \mathrm{RH}$ in the mid-troposphere). It is also consistent with the layer-averaged $\mathrm{RH}$ profiles estimated by the Indian team involved in the Megha-Tropiques mission, although further constraining the retrieval by NCEP/NCAR outputs (Venkat Ratnam et al., 2013; Gohil et al., 2013). A 1D-variational technique exploring SAPHIR data should further improve the estimation of RH.

Following this work, our current efforts focus on the estimation of the conditional error associated to the retrieval itself. Indeed, because the widths and altitudes of the weighting functions of SAPHIR are strongly dependent on the thermodynamical state of the atmosphere (the drier the atmosphere, the wider the layer; the maximum of sensitiv- ity shifting from the upper troposphere towards the midtroposphere), it is clearly expected that the robustness of the RH estimation will be conditioned by the state of the atmosphere. The aim will be to provide the probability density function of the relative humidity on given BTs (a given state of the atmosphere) and thus address the issue of nonGaussian distribution of the relative humidity at a given height. The knowledge of such information fits into the current work done within the Global Energy and Water Cycle Experiment (GEWEX) Water Vapor Assessment (G-VAP: http://www.gewex-vap.org) to better characterize the observational records, together with their uncertainties.

Acknowledgements. The authors thanks the LMD/ABC(t)/ARA group for producing and making available to the community their "ARSA" radiosounding database (available from http://ara.abct.lmd.polytechnique.fr/index.php?page=arsa), and more specifically Noelle Scott for her advice on the use of ARSA for training purposes. Gaelle Clain is also acknowledged for her work on the CINDY/DYNAMO/AMIE profiles and their collocation with Megha-Tropiques. The help of R. Johnson, P. Ciesielski (CSU) and J. Wang (NCAR) with the CINDY/DYNAMO/AMIE radiosounding data set was greatly appreciated. The advice of P. Eriksson were welcomed and helped to improve the manuscript. Finally, the two anonymous reviewers are thanked for their comments and questions that improved the description of the work. The different statistical models have been implemented and optimized using either Matlab (the somtoolbox package is freely available from the Laboratory of Computer and Information Science) or the $\mathrm{R}$ free software (the gam and AMORE packages are freely available from the Comprehensive R Archive Network - CRAN).

Edited by: S. J. Munchak

\section{References}

Aires, F. and Prigent, C.: A new neural network approach including first guess for retrieval of atmospheric water vapor, cloud liquid water path, surface temperature, and emissivities over land from satellite microwave observations, J. Geophys. Res., 106, 1488714907, 2001.

Aires, F., Bernardo, F., Brogniez, H., and Prigent, C.: An innovative calibration method for the inversion of satellite observations, J. Appl. Meteor. Climatol., 49, 2458-2473, 2010.

Aires, F., Prigent, C., Bernardo, F., Jimenez, C., Saunders, R., and Brunel, P.: A Tool to Estimate Land-Surface Emissivities at Microwave frequencies (TELSEM) for use in numerical weather prediction, Q. J. Roy. Meteorol. Soc., 137(A), 690-699, 2011.

Aires, F., Bernardo, F., and Prigent, C.: Atmospheric water-vapour profiling from passive microwave sounders over ocean and land. Part I: Methodology for the Megha-Tropiques mission, Q. J. Roy. Meteorol. Soc., 139, 852-864, 2013.

Anandhi, A., Srinivas, V., Nanjundiah, R., and Kumar, D.: Downscaling precipitation to river basin in India for IPCC SRES scenarios using support vector machine, Int. J. Climatol., 28, 401420, 2008. 
Aumann, H., Chahine, M., Gautier, C., Goldberg, M., Kalnay, E., McMillin, L., Revercomb, H., Rosenkranz, P., Smith, W., Staelin, D., Strow, L., and Sussking, J.: AIRS/AMSU/HSB on the Aqua mission: design, science objectives, data products and processing systems, IEEE Trans. Geosci. Remote Sens., 41, 253-264, 2003.

Balabin, R. and Lomakina, E.: Support vector machine regression (SVR/LS-SVM). An alternative to neural networks (ANN) for analytical chemistry? Comparison of nonlinear methods on near infrared (NIR) spectroscopy data, Analyst, 136, 1703-1712, 2011.

Beckmann, B. and Buishand, T.: Statistical downscaling relationships for precipitations in The Netherlands and North Germany, Int. J. Climatol., 22, 15-32, 2002.

Belsley, D., Kuh, E., and Welsch, R.: Regression Diagnostics, in: Regression Diagnostics: identifying influential data and sources of collinearity, John Wiley \& Sons Inc., 1980.

Bennartz, R. and Bauer, P.: Sensitivity of microwave radiances at $85-183 \mathrm{GHz}$ to precipitating ice particles, Radio Sci., 38, 8075, doi:10.1029/2002RS002626, 2003.

Bishop, C.: Neural networks for pattern recognition, vol. 1, Clarendon Press, Oxford, 1995.

Blackwell, W.: A neural-network technique for the retrieval of atmospheric temperature and moisture profiles from high spectral resolution sounding data, IEEE Trans. Geosci. Remote Sens., 43, 2535-2546, 2005.

Blankenship, C., Al-Khalaf, A., and Wilheit, T.: Retrieval of Water Vapor Profiles Using SSM/T-2 and SSM/I Data, J. Atmos. Sci., 57, 939-955, 2000.

Brogniez, H. and Pierrehumbert, R.: Using microwave observations to assess large-scale control of free tropospheric water vapor in the mid-latitudes, Geophys. Res. Lett., 33, L14801, doi:10.1029/2006GL026240, 2006.

Brogniez, H., Kirstetter, P.-E., and Eymard, L.: Expected improvements in the atmospheric humidity profile retrieval using the Megha-Tropiques microwave payload, Q. J. Roy. Meteorol. Soc., 139, 842-851, doi:10.1002/qj.1869, 2013.

Buehler, S. and John, V. O.: A simple method to relate microwave radiances to Upper Tropospheric Humidity, J. Geophys. Res., 110, D02110, doi:10.1029/2004JD005111, 2004.

Buehler, S. A., Kuvatov, M., and John, V. O.: Comparison of microwave satellite humidity data and radiosonde profiles: A case study, J. Geophys. Res., 109, D13103, doi:10.1029/2004JD004605, 2004.

Buehler, S. A., Kuvatov, M., and John, V. O.: Scan asymmetries in AMSU-B data, Geophys. Res. Lett., 32, L24810, doi:10.1029/2005GL024747, 2005.

Cabrera-Mercadier, C. and Staelin, D.: Passive microwave relative humidity retrievals using feedforward neural networks, IEEE Trans. Geosci. Remote Sens., 33, 1324-1328, 1995.

Cawley, G. and Talbot, N.: Preventing Over-Fitting during Model Selection via Bayesian Regularisation of the Hyper-Parameters, J. Machine Learning Res., 8, 841-861, 2007.

Chen, S., Billings, S., and Luo, W.: Orthogonal least squares methods and their application to non-linear system identification, Int. J. Control, 50, 1873-1896, 1989.

Ciesielski, P., Yu, H., Johnson, R., Yoneyama, K., Katsumata, M., Long, C., Wang, J., Loehrer, S., Young, K., Williams, S., Brown, W., Braun, J., and Van Hove, T.: Quality-controlled upper-air sounding dayaset for DYNAMO/CINDY/AMIE: de- velopment and corrections, J. Atmos. Oceanic Technol., 31, 741764, doi:10.1175/JTECH-D-13-00165.1, 2015.

Clain, G., Brogniez, H., Payne, V. H., John, V. O., and Ming, L.: An assessment of SAPHIR calibration using quality tropical soundings, J. Atmos. Oceanic Technol., 32, 61-78, doi:10.1175/JTECH-D-14-00054.1, 2015.

Davis, J., Eder, B., Nychka, D., and Yang, Q.: Modeling the effects of eteorology on Ozone in Houston using cluster analysis and generalized additive models, Atmos. Environ., 32, 2505-2520, 1998.

Deblonde, G. and English, S.: Evaluation of the FASTEM-2 fast microwave oceanic surface emissivity model, Tech. Proc., 2001.

Durre, I., Vose, R., and Wuertz, D.: Overview of the Integrated Global Radiosonde Archive, J. Climate, 19, 53-68, 2006.

English, S., Guillou, C., Prigent, C., and Jones, D.: Aircraft measurements of water vapour continuum absorption at millimetre wavelengths, Q. J. Roy. Meteorol. Soc., 120, 603-625, 1994.

Fetzer, E., Hulley, G., Lambrigsten, B., Manning, E., Blaisdell, J., Iredell, L., Sussking, J., Warner, J., Wei, Z., and Blackwell, W.: AIRS/AMSU/HSB version 6 changes from version 5, Tech. rep., NASA Jet Propulsion Laboratory, 2013.

Franquet, S.: Contribution à l'étude du cycle hydologique par radiométrie hyperfréquence: algorithme de restitution (réseaux de neurones) et validation pour la vapeur d'eau (AMSU, SAPHIR) et les précipitations (AMSU, radars au sol BALTRAD), $\mathrm{PhD}$ thesis, Université de Paris 7, 2003.

Gierens, K., Schumann, U., Helten, M., Smit, H., and Marenco, A.: A distribution law for relative humidity in the upper troposphere and lower stratosphere derived from three years of MOZAIC measurements, Ann. Geophys., 17, 1218-1226, doi:10.1007/s00585-999-1218-7, 1999.

Gohil, B., Gairola, R., Mathur, A., Varma, A., Mahesh, C., Gangwar, R., and Pal, P.: Algorithms for retrieving geophysical parameters from the MADRAS and SAPHIR sensors of the MeghaTropiques satellites: Indian scenario, Q. J. Roy. Meteorol. Soc., 139, 954-963, 2013.

Goldberg, M., Crosby, D., and Zhou, L.: The Limb Adjustment of AMSU-A Observations: Methodology and Validation, J. Appl. Meteor., 40, 70-83, 2000.

Hall, A. and Manabe, S.: Effect of water vapor feedback on internal and anthropogenic variations of the global hydrological cycle $\varnothing$, J. Geophys. Res., 105, 6935-6944, 2000.

Hastie, T. and Tibshirani, R.: Generalized Additive Models, Chapman \& Hall/CRC, 1990.

Hastie, T., Tibshirani, R., and Friedman, J.: The elements of statistical learning, Springer, 2009.

Haykin, S.: Neural Networks: A Comprehensive Foundation, IEEE Press, New York, NY, USA, 1994.

Held, I. and Soden, B.: Water vapour feedback and global warming, Annu. Rev. Energy Environn., 25, 441-475, 2000.

Held, I. and Soden, B.: Robust responses of the hydrological cycle to global warming, J. Climate, 19, 3354-3360, 2006.

Hong, G., Heygster, G., Miao, J., and Kunzi, K.: Detection of tropical deep convective clouds from AMSU-B water vapor channels measurements, J. Geophys. Res., 110, D05205, doi:10.1029/2004JD004949, 2005.

Houze, R. and Betts, A.: Convection in GATE, Rev. Geophys., 19, 541-576, 1981. 
Karbou, F., Aires, F., Prigent, C., and Eymard, L.: Potential of Advanced Microwaves Sounding Unit-A (AMSU-A) and AMSU-B measurements for atmospheric temperature and humidity profiling over land, J. Geophys. Res., 110, D07109, doi:10.1029/2004JD005318, 2005.

Karouche, N., Goldstein, C., Rosak, A., Malassingne, C., and Raju, G.: Megha-Tropiques satellite mission: in flight performances results, Geosci. Remote Sens. Symposium (IGARSS), 4684-4687, doi:10.1109/IGARSS.2012.6350420, 2012.

Kohonen, T.: Self-organizing formation of topologically correct feature maps, Biological Cybernetics, 46, 59-69, 1982.

Kohonen, T.: Self-Organizing maps, Springer series in Informations Sciences, 3rd edn., 2001.

Kuo, C., Staelin, D., and Rosenkranz, P.: Statistical iterative scheme for estimating atmospheric relative humidity profiles, IEEE Transactions on Geoscience and Remote Sensing, 32, 254-260, 1994.

Laurent, R. T. and Cook, R.: Leverage, local influence and curvature in nonlinear regression, Biometrika, 80, 99-106, 1993.

Lee, Y., Wahba, G., and Ackerman, S.: Cloud classification of satellite radiance data by Multicategory Support Vectore Machines, J. Atmos. Oceanic Technol., 21, 159-169, 2004.

Liu, Q. and Weng, F.: One-dimensional variational retrieval algorithm of temperature, water vapor and cloud water profiles from Advanced Microwave Sounding Unit (AMSU), IEEE Trans. Geosci. Remote Sens., 43, 1087-1095, 2005.

Mallet, C., Moreau, E., Casagrande, L., and Klapisz, C.: Determination of integrated cloud liquid water path and total precipitable water from SSM/I data using a neural network algorithm, Int. J. Remote Sens., 23, 661-674, 1993.

Matricardi, M., Chevallier, F., Kelly, G., and Thépaut, J.: An improved general fast radiative transfer model for the assimilation of radiance observations, Am. Meteorol. Soc., 130, 153-173, 2004.

Mestre, O. and Hallegatte, S.: Predictors of tropical cyclone numbers and extreme hurricane intensities over the North Atlantic using Generalized Additive and Linear Models, J. Climate, 22, 633-648, 2009.

Moradi, I., Soden, B., Ferraro, R., Arkin, P., and Vömel, H.: Assessing the quality of humidity measurements from global operational radiosonde sensors, J. Geophys. Res., 118, 8040-8053, 2013.

Nash, J., Smout, R., Oakley, T., Pathack, B., and Kurnosenko, S.: WMO intercomparison of high quality radiosonde systems : Final report, WMO Report, p. 118, 2005.

Pierrehumbert, R. and Roca, R.: Evidence for control of Atlantic subtropical humidity by large-scale advection, Geophys. Res. Lett., 25, 4537-4540, 1998.

Pierrehumbert, R., Brogniez, H., and Roca, R.: On the relative humidity of the Earth's atmosphere, in: The Global Circulation of the Atmosphere, Princeton University Press, 143-185, 2007.

Prigent, C., Aires, F., and Rossow, W.: Land surface microwave emissivities over the globe for a decade, B. Am. Meteorol. Soc., 87, 1572-1584, 2006.

Qu, Z.: Cooperative Control of Dynamical Systems, 2009.

Read, W. G., Waters, J. W., Wu, D. L., Stone, E., Shippony, Z., Smedley, A. C., Smallcomb, C. C., Oltmans, S., Kley, D., Smit, H. G. J., Mergenthaler, J., and Karki, M.: UARS Microwave Limb Sounder upper tropospheric humidity measure- ment: Method and validation, J. Geophys. Res., 106, 3220732258, 2001.

Read, W. G., Lambert, A., Bacmeister, J., Cofield, R. E., Christensen, L. E., Cuddy, D. T., Daffer, W. H., Drouin, B. J., Fetzer, E., Froidevaux, L., Fuller, R., Herman, R., Jarnot, R. F., Jiang, J. H., Jiang, Y. B., Kelly, K., Knosp, B. W., Kovalenko, L. J., Livesey, N. J., Liu, H.-C., Manney, G. L., Pickett, H. M., Pumphrey, H. C., Rosenlof, K. H., Sabounchi, X., Santee, M. L., Schwartz, M. J., Snyder, W. V., Stek, P. C., Su, H., Takacs, L. L., Thurstans, R. P., Vömel, H., Wagner, P. A., Waters, J. W., Webster, C. R., Weinstock, E. M., and Wu, D. L.: Aura Microwave Limb Sounder upper tropospheric and lower stratospheric H2O and relative humidity with respect to ice validation, J. Geophys. Res., 112, D24S35, doi:10.1029/2007JD008752, 2007.

Rieder, M. and Kirchengast, G.: Physical-statistical retrieval of water vapor profiles using SSM/T-2 sounder data, Geophys. Res. Lett., 26, 1397-1400, 1999.

Roca, R., Bergès, J.-C., Brogniez, H., Capderou, M., Chambon, P., Chomette, O., Cloché, S., Fiolleau, T., Jobard, I., Lémond, J., Ly, M., Picon, L., Raberanto, P., Szantai, A., and Viollier, M.: On the water and energy cycles in the Tropics, C.R. Geoscience, 342, 390-402, 2010.

Rumelhart, D., Hinton $\dagger$, G., and Williams, R.: Learning internal representation by error propagation. in: Parallel Distributed Processing: Explorations in the Microstructure of Cognition, vol. 1, edited by: Rumelhart, D. E. and McClelland, J. L., 1986.

Schaerer, G. and Wilheit, T. T.: A passive microwave technique for profiling of atmospheric water vapor, Radio Sci., 14, 371-375, 1979.

Schmetz, J. and Turpeinen, O.: Estimation of the Upper Tropospheric Relative Humidity field from METEOSAT water vapor image data, J. Appl. Meteor., 27, 889-899, 1988.

Scholkopf, B. and Smola, A.: Learning with Kernels, MIT Press, 2002.

Sherwood, S., Roca, R., Weckwerth, T., and Andronova, N.: Tropospheric water vapor, convection and climate, Rev. Geophys., 48, RG2001, doi:10.1029/2009RG000301, 2010.

Soden, B. and Bretherton, F.: Upper Tropospheric Relative Humidity from the GOES 6.7 Channel: Method and Climatology for July 1987, J. Geophys. Res., 98, 16669-16688, 1993.

Spencer, R. and Braswell, W.: How dry is the tropical free troposphere? Implications for a global warming theory, B. Am. Meteorol. Soc., 78, 1097-1106, 1997.

Stephens, G.: On the relationship between water vapor over the oceans and sea surface temperature, J. Climate, 3, 634-645, 1990.

Stephens, G., Jackson, D., and Wittmeyer, I.: Global observations of Upper-Tropospheric water vapor derived from TOVSQ radiance data, J. Climate, 9, 305-326, 1996.

Student: The probable error of a mean, Biometrika, 6, 1-25, 1908.

Sun, B.-Y., Huang, D.-S., and Fang, H.-T.: Lidar signal denoising using Least-Squares Support Vector Machine, IEEE Signal Processing Lett., 12, 101-104, 2005.

Suykens, J. A., Gestel, T. V., de Brabanter, J., de Moor, B., and Vandewalle, J.: Least Squares Support Vector Machines, World Scientific, 2002.

Tripathi, S., Srinivas, V., and Nanjundiah, R.: Downscaling of precipitation for climate change scenarios: a support vectore machine approach, J. Hydrol., 330, 621-640, 2006. 
Ulaby, F., Moore, R., and Fung, A.: Microwave Remote Sensing Active and Passing Vol. 1: Microwave Remote Sensing Fundamentals and Radiometry, vol. 1, Addison-Wesley, 1981.

Underwood, F.: Describing long-term trends in precipitation using generalized additive models, J. Hydrol., 364, 285-297, 2009.

Van Dang, H., Lambrigsten, B., and Manning, E.: AIRS/AMSU/HSB version 6 Level 2 performance and test report, Tech. rep., NASA Jet Propulsion Laboratory, 2012.

Venkat Ratnam, M., Basha, G., Krishna Murthy, B., and Jayaraman, A.: Relative humidity distribution from SAPHIR experiment onboard Megha-Tropiques satellite mission: Comparison with global radiosonde and other satellite and reanalysis datasets, J. Geophys. Res., 118, 9622-9630, 2013.

Vrac, M., Marbaix, P., Paillard, D., and Naveau, P.: Non-linear statistical downscaling of present and LGM precipitation and temperatures over Europe, Clim. Past, 3, 669-682, doi:10.5194/cp3-669-2007, 2007.
Wang, J. and Zhang, L.: Systematic Errors in Global Radiosonde Precipitable Water Data from Comparisons with Ground-Based GPS Measurements, J. Climate, 21, 2218-2238, 2008.

Wood, S.: Stable and efficient multiple smoothing parameter estimation for generalized additive models, J. Am. Statist. Assoc., 99, 673-686, 2004.

Wood, S.: Generalized Additive Models, an Introduction with R, Chapman \& Hall/CRC, 2006.

Wun-Hua, C., Jen-Ying, S., and Soushan, W.: Comparison of support-vector machines and back propagation neural networks in forecasting the six major Asian stock, Inderscience Enterprises Ltd, 1, 49-67, 2006. 